\title{
First description of sarcoptic mange in the endangered Iberian lynx (Lynx pardinus): clinical and epidemiological features
}

\author{
Alvaro Oleaga $^{1}$ (I) $\cdot$ Amalia García $^{2} \cdot$ Ana Balseiro $^{3} \cdot$ Rosa Casais $^{3} \cdot$ Enrique Mata $^{4} \cdot$ Elena Crespo $^{5}$
}

Received: 3 December 2018 / Revised: 9 April 2019 / Accepted: 12 April 2019 / Published online: 24 April 2019

(C) Springer-Verlag GmbH Germany, part of Springer Nature 2019

\begin{abstract}
A 6-month-old female Iberian lynx (Lynx pardinus) cub that was severely affected by mange died in September 2016 in the Montes de Toledo (Spain) with crusts and fissures on its face, outer ears, nipples and footpads. The body condition of the cub was very poor, and it also had a mandibular abscess and a severely ankylosed luxation on its left knee. After confirming that the origin of the deceased cub's dermal lesions was Sarcoptes scabiei, the subsequent search for ectoparasites and a comparison of histopathological and immunohistochemical findings in all sympatric lynxes handled $(n=30)$ and submitted for necropsy $(n=$ 4) during 2016 and 2017 revealed the presence of S. scabiei mites and/or milder mange compatible lesions in five members of her family group, which was treated against mange together with two exposed contiguous family groups. An ELISA developed by the authors showed the presence of antibodies against $S$. scabiei in the deceased female cub and one brother. The presence of concomitant immunosuppressive factors in the dead female cub and the results obtained for the other sympatric lynxes studied since 2016 suggest that S. scabiei had a limited effect on immune-competent Iberian lynxes in the local population of the Montes de Toledo. However, a different evolution and relevance of sarcoptic mange in different populations - or even in the same one in the presence of immunosuppressive factors - cannot be ruled out, thus confirming the need for further research in order to attain a complete comprehension of the epidemiology and the real threat that this ectoparasitic disease may imply for L. pardinus.
\end{abstract}

Keywords Endangered species $\cdot$ Iberian lynx $\cdot$ Lynxpardinus $\cdot$ Sarcoptic mange $\cdot$ Sarcoptes scabiei $\cdot$ Wildlife sanitary surveillance

\section{Introduction}

Despite the encouraging results obtained during the last few years, the Iberian lynx (Lynx pardinus) is still one of the most

Alvaro Oleaga and Amalia García contributed equally to this work.

Alvaro Oleaga

alvaroleaga@yahoo.es

1 SERPA, Sociedad de Servicios del Principado de Asturias S.A., 33203 Gijón, Spain

2 Centro de Estudio para las Rapaces Ibéricas (CERI); GEACAM; JCCM, Toledo, Spain

3 SERIDA, Servicio Regional de Investigación y Desarrollo Agroalimentario, Centro de Biotecnología Animal, Gijón, Spain

4 Centro de Análisis y Diagnóstico de la Fauna Silvestre de Andalucía (CAD), Málaga, Spain

5 Centro de Recuperación de Fauna Silvestre "El Chaparrillo"; GEACAM, JCCM, Ciudad Real, Spain endangered cat species in the world and is considered an "endangered" species on the 2015 International Union for Conservation of Nature (IUCN) Red List (Rodríguez and Calzada 2015), with an estimated population of 483 individuals reported in the 2016 census (Simon 2017). The small population size, together with demographic bottlenecks and the associated loss of genetic diversity suffered by its populations (Johnson et al. 2004; Abascal et al. 2016), have made this species particularly vulnerable to several threats, including pathogenic agents (Meli et al. 2009, 2010).

A number of infectious agents have threatened the endangered Iberian lynx during recent decades and have either decimated the populations of its main prey (with a dramatic decline in rabbit - Oryctolagus cuniculus - abundance after the appearance of myxomatosis in the 1950s and the rabbit hemorrhagic disease - RHD - in 1989 [Calvete et al. 2002]) or have directly produced illness (and even deaths) in these wild felines' populations (Meli et al. 2010). Infectious diseases were reported as being the most important cause of death in 78 Iberian lynxes that were radio-tagged in Spain between 2006 and 2011, accounting for as much as $38.5 \%$ of all 
recorded mortalities (López et al. 2014). In this respect, an outbreak of feline leukemia virus (FeLV) during 2007 severely affected (Meli et al. 2010) the small Iberian lynx population in Doñana National Park (one of the only two remaining stable populations at that time). Subsequent studies carried out to investigate the transmission of FeLV from affected lynxes to cats stressed the particular susceptibility of Iberian lynxes to infectious diseases (Geret et al. 2011). Other infectious diseases, such as tuberculosis, pasterellosis, clostridiosis, feline parvovirus infection, or Aujeszky's disease virus infection, have been confirmed to affect the Iberian lynx (Millán et al. 2009; López et al. 2014; Masot et al. 2017), but few works have been published with regard to the effects of macroparasites and ectoparasites on L. pardinus, including their effect as pathogens or as vectors of pathogens (Millán et al. 2007).

Sarcoptic mange, which is caused by the burrowing mite Sarcoptes scabiei, is a relevant illness owing to its zoonotic condition and economical relevance in domestic animals, while from an ecological point of view, sarcoptic mange may be an important problem for isolated or small size populations (Martin et al. 1998; Kalema-Zikusoka et al. 2002). Various feline species have been described to be affected by sarcoptic mange in the wild, including the cheetah (Acinonyx jubatus), the serval (Felis serval), the African lion (Panthera leo), the leopard (Panthera pardus), and the Eurasian lynx (Lynx lynx) (Munson et al. 2010). In the last case, sarcoptic mange was reported to be the most frequent infectious disease in Sweden, affecting up to $22 \%$ of the non-hunted dead lynxes reported (Ryser-Degiorgis et al. 2005a). The disease was considered to have contributed to the decrease in the Swedish lynx population during the first decade of a major mange epidemic (1980-1990, Mörner 1992), although after its hunting was prohibited, the population recovered in 1999 (RyserDegiorgis et al. 2005b). In Switzerland, mange was first detected in the small and inbred reintroduced Eurasian lynx population in 1999 (Ryser-Degiorgis et al. 2002) and increased the overall percentage of infectious causes of mortality by up to $40 \%$ (Schmidt-Posthaus et al. 2002), although no important related population decline was reported (von Arx et al. 2004).

Sarcoptic mange is endemic in Spanish red fox (Vulpes vulpes) populations (Gortázar et al. 1998), a confirmed prey of the Iberian lynx when sympatric (Palomares et al. 1996). Nevertheless, no Iberian lynx (nor red fox) was confirmed to be affected by mange in a previous study focused on the detection of ectoparasites in the Iberian lynx ecosystem (Millán et al. 2007), and no clinical case of sarcoptic mange has, to the best of our knowledge, been reported in the Iberian lynx population to date.

This work represents the first reported case of sarcoptic mange in free-living Iberian lynx. The aims of the present work are (i) to summarize clinical features of the reported fatal case, (ii) to assess the possible presence and relevance of sarcoptic mange lesions and/or mites in sympatric Iberian lynxes, (iii) to develop and evaluate an enzyme-linked immunosorbant assay (ELISA) for the detection of antibodies against $S$. scabiei in the Iberian lynx, and (iv) to discuss the possible relevance and management implications of the reported outbreak and the detection of sarcoptic mange in this endangered species.

\section{Materials and methods}

\section{Studied animals and sample collection}

A 6-month-old female Iberian lynx cub (from here on denominated as "N4-Keres") was admitted to the Wildlife Rehabilitation Center "CERI" (Centro de Estudios para las Rapaces Ibéricas) on September the 12th 2016. This lynx was born in the framework of the LIFE-IBERLINCE program: "Recuperation of the historical distribution of the Iberian lynx (Lynx pardinus) in Spain and Portugal" (LIFE10NAT/ES/570), which began reintroducing this wild cat into western Sierra Morena and the Montes de Toledo (South-Central Spain) in 2014.

The cub was found seriously ill at a private country house in the municipality of Mazarambroz (Montes de Toledo, X396458, Y4382440 Central Spain), and was extremely weak and cachectic. The cub was trapped by field technicians working for the Government of Castilla-La Mancha and taken to the Wildlife Rehabilitation Center, where it died $29 \mathrm{~h}$ after admission, despite the intensive care provided. After death, a complete necropsy was performed at the CERI Wildlife Rehabilitation Center according to the work protocol established for this species (https://www.lynxexsitu.es/ ficheros/documentos.../Manual_Sanitario_Lince_Ib_2014. pdf). After a thorough external examination and the collection of body measurements, skin scrapes were taken from the cub's ears, face, and footpads for the detection and identification of ectoparasites, and blood was collected from its jugular vein for molecular and serological studies. The animal's skin was removed and thoroughly reviewed after necropsy, in small skin patches of $10 \times 10 \mathrm{~cm}$ using an Olympus SZX9 (10 $57 \times$ ) magnifier for the detection and collection of ectoparasites. Several tissues (brain, heart, lungs, intestine, spleen, kidney, liver, and scapular lymph nodes) and skin samples from eight anatomical regions (ear, lip, nose, periorbital, forelimb, hind limb, belly, and back) were taken and stored in $10 \%$ neutral formalin for their subsequent histopathological and immunohistochemical analysis. Oropharyngeal and rectal swabs, in addition to samples of the brain, blood, heart, lung, intestine, spleen, kidney, and liver, were also collected for serological, parasitological, and molecular analyses regarding the different pathogen agents studied in the Iberian lynx, as previously described 


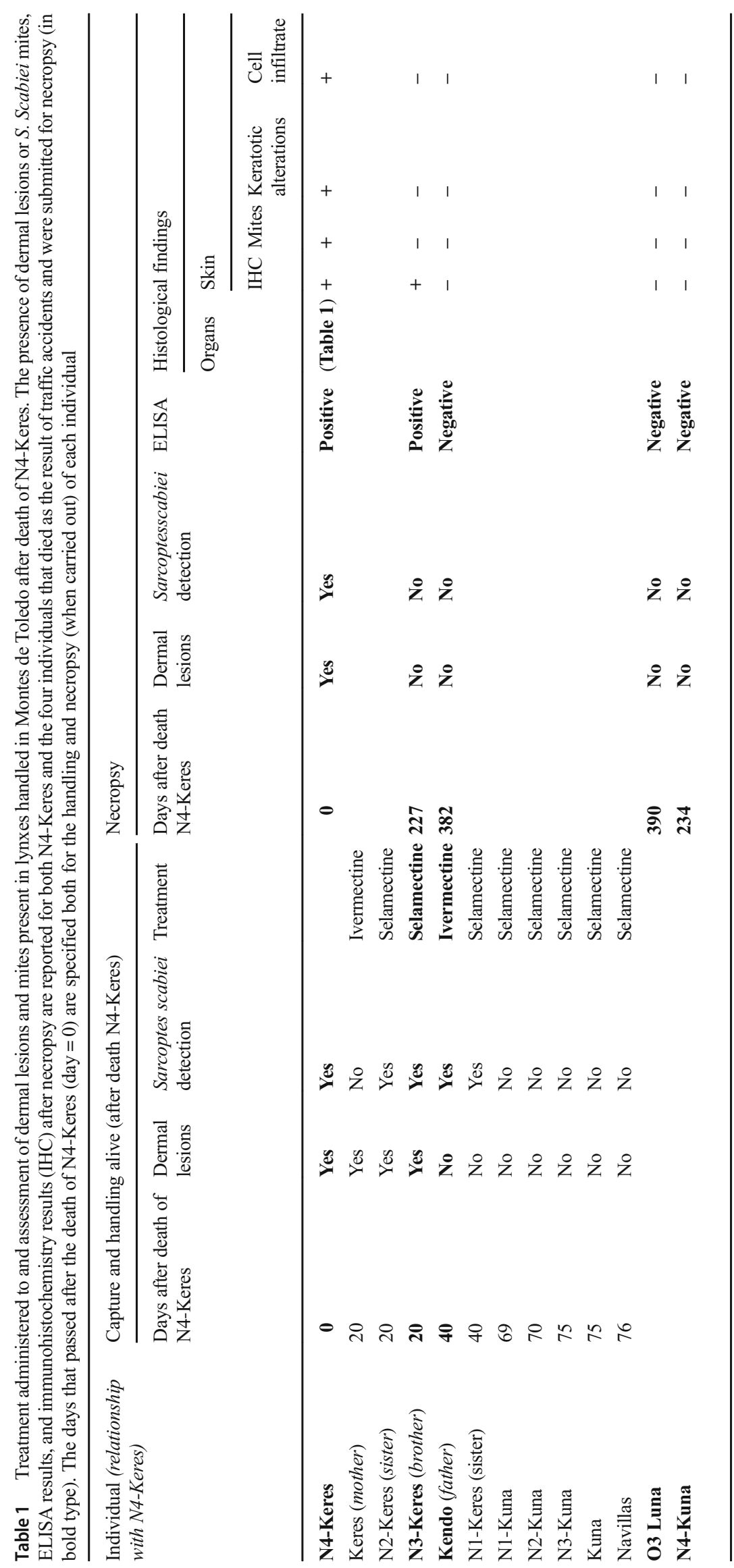


(Hofmann-Lehmann et al. 1996; Ramsauer et al. 2007; Meli et al. 2009). Liver and gastric content for toxicological analyses and excrements for parasitological studies were also collected. The subsequent parasitological and microbiological diagnostic analyses were performed at the "Centro de Análisis y Diagnóstico de la Fauna Silvestre (CAD)", Málaga-Andalucía-, and the "Servicio Regional de Investigación y Desarrollo Agroalimentario (SERIDA)", Gijón-Asturias (Spain).

It is important to mention here that N4-Keres' father (Kendo) was also the father to a contiguous family group (of which the mother was the female, Kuna). The data attained from the necropsy and subsequent diagnostic tests carried out on N4-Keres showed the need to study and treat the other members of its family pack, along with the members of the contiguous family group for mange, since Kendo was the father of both (see Table 1). Since the death of N4-Keres, all the lynxes captured and handled in the Montes de Toledo during 2016 and $2017(n=30)$ have been subjected to skin scrapings and a thorough review for the detection of dermal lesions. The adults were captured by using trap cages with bait. They were anesthetized in order to monitor their health status, and blood samples, scrapings of the ear and face, along with oropharyngeal and rectal swabs, were collected for PCR studies, after which they were fitted with tracking collars. The cubs were also captured, although they were not anesthetized. After being examined in the cage, scrapings were taken from their ears, and FelV vaccinations and transponder placements were carried out. The two family groups of the females Keres and Kuna and their male (Kendo) were treated in 2016 with Selamectin (cubs) and Ivermectin (adults, with the exception of Kuna, who was treated with Selamectin, Table 1).

Four Iberian lynxes, which died in 2017 as a consequence of traffic accidents in the Montes de Toledo, were submitted to CERI for necropsy. These four individuals were the father (Kendo) and N4-Keres' brother (denominated as N3-Keres), one of Kendo's daughters in a sympatric family group (N4Kuna) and a female cub (O3-Luna) from another family group living near to those of Keres and Kuna (see Table 1). The performance of their necropsies was carried out according to the established work protocol for this species and was completed with skin scrapings and the collection of blood and skin samples for parasitological, histopathological, and serological studies, and for comparison with the data obtained for N4Keres in 2016.

Finally, sera from 11 mange-free lynxes belonging to the Iberian lynx Breeding Centers were collected for the development and evaluation of an enzyme-linked immunosorbant assay (ELISA) for the detection of antibodies against $S$. scabiei in the Iberian lynx.

\section{Histology and immunohistochemistry}

Samples taken for histopathological analysis from N4-Keres and the four lynxes that had died owing to traffic accidents (Kendo, N3-Keres, N4-Kuna, and O3-Luna) were fixed in $10 \%$ neutral formalin, embedded in paraffin using standard procedures and stained with hematoxylin and eosin (HE). The kidneys were also stained with Congo Red for amyloid, periodic acid-Schiff stain for polysaccharides and Grocott's methenamine silver stain for basal membranes.

For the immunohistochemical study, 3- $\mu \mathrm{m}$ sections of skin samples from the ear, lip, nose, periorbital, forelimb, hind limb, belly, and back from the five lynxes upon which necropsies had been carried out were collected and immunostained using the Avidin Biotin Complex (ABC, Vector Laboratories, California, USA) method. Briefly, the sections were deparaffinized and rehydrated with tap water. The samples were then treated in order to inactivate the endogenous peroxidase by means of incubation with methanol containing $3 \% \mathrm{H}_{2} \mathrm{O}_{2}$ for $10 \mathrm{~min}$, washed with water for $10 \mathrm{~min}$, and then treated to prevent unspecific binding by using a $15-\mathrm{min}$ incubation with $10 \%$ normal goat serum (DAKO, Glostrup, Denmark) 3\% bovine serum albumin (BSA) in Tris buffer saline (TBS) (5 mM Tris/ $\mathrm{HCl} \mathrm{pH} 7.6,136 \mathrm{mM} \mathrm{NaCl})$. The tissue sections were incubated overnight at $4{ }^{\circ} \mathrm{C}$ with a rabbit polyclonal antiserum to the $S$. scabiei $\mathrm{Ss} \lambda 15$-derived polipeptide (Casais et al. 2007) diluted 1:700 in TBS and then washed three times with TBS. The samples were subsequently incubated with goat anti-rabbit serum (Vector Laboratories, California, USA) diluted 1:200 in TBS for $30 \mathrm{~min}$ at room temperature and washed three times with TBS followed by incubation with the $\mathrm{ABC}$ kit in TBS for $30 \mathrm{~min}$ at room temperature. Finally, the sections were incubated with the substrate 3, 3'-diaminobenzidine tetrahydrochloride (DAB, Sigma, St. Louis, USA) for $10 \mathrm{~min}$ and washed with TBS and water. After staining with hematoxylin for $45 \mathrm{~s}$, the preparations were dehydratated, pasted with DPX mountant for histology (Sigma, St. Louis, USA), and were then observed using an Olympus BH-2 light microscope and photographed using an Olympus DP-12 digital camera. A positive control (skin from an infected chamois) was used in each run. Rabbit preimmune serum was used as a negative control on an additional slide from each section.

\section{ELISA}

Sera from 16 lynxes were tested by using an indirect ELISA, based on the $S$. scabiei recombinant antigen $\operatorname{Ss} \lambda 20 \Delta B 3$ (Casais et al. 2007), previously used for the immunodiagnosis of S. scabiei in various animal species (Casais et al. 2007; Oleaga et al. 2008; Falconi et al. 2010; Casais et al. 2013; Casais et al. 2015). The ELISA was adapted for the diagnosis of the disease in lynx by determining the best conjugate and its 
optimal concentration performing a preliminary checkerboard titration using reference sera samples. The best signal-to-noise ratio of the optical densities (ODs) of the positive and negative reference sera (Prieto et al. 2014) was obtained using goat anti-cat horseradish peroxidase-conjugated (SIGMA, St. Louis, USA) diluted 1500 times in blocking solution. The peroxidase substrate employed was $3,3^{\prime}, 5,5^{\prime}$ tetramethylbenzidine liquid substrate (TMB) (SIGMA, St. Louis, USA).

The gold standard technique used to classify the animals was the identification of S. scabiei mites in skin scrapings carried out during handlings or after death by means of the pathological and immunohistochemical study of those animals that had been run over. We established three groups of animals: (A) the lynx N4-Keres (confirmed to be harboring the mite and seriously ill at the time of death/sampling), (B) the group of 4 lynxes (Kendo, N3-Keres. N4-Kuna and O3Luna) which had died as the result of collisions with vehicles and were submitted for necropsy, and (C) a group of 11 mange-free lynxes from the Iberian lynx Breeding Centers.

Negative and positive reference sera consisted of a serum collected from a mange-free lynx (born in captivity in the Iberian lynx Breeding Program) and the confirmed mangy lynx (N4-Keres), respectively, were added to each microtiter plate for normalization. The raw data of the measured OD were normalized as recommended by Sanchez et al. (2012) by expressing them as a percentage of the positive control in a ratio that corrected for the measured OD of the negative control according to the following formula:

$$
\begin{aligned}
\% \text { relativeOD }= & \frac{\text { ODsample_serum }- \text { ODnegative_control }}{\text { ODpositive_control-ODnegative_control }} \\
& \times 100 .
\end{aligned}
$$

The cut-off level of the ELISA test was calculated as the mean of the \% relative OD $450 \mathrm{~nm}$ plus three times the standard deviation of a group of 11 Sarcoptes-free lynx (Bornstein and Wallgren 1997; Hollanders et al. 1997; Jacobson 1998; Zimmermann and Kircher 1998).

\section{Results}

\section{Pathological studies}

\section{Gross lesions}

The female cub, N4-Keres, weighed $1600 \mathrm{~g}$ and had a very poor body condition at admission. The carcass was in perfect state of preservation at necropsy. The general aspect of the skin was irregular and shabby, with the most evident alterations on the neck and face. Crusts and fissures were present on the face, outer ears, nipples, and footpads. Despite the alterations observed on the skin, no alopecic areas were found, and there were only small patches of less hair density in the abovementioned crusted areas. A large number of mites were confirmed both on the skin scrapings and during the thorough revision of the removed skin, mainly on the head, neck, and limbs. All detected mites were identified as S. scabiei according to Wall and Shearer (1997), including all stages, and were collected and preserved in $70 \%$ ethanol. Skin from the caudal and perianal regions showed the presence of adhered fecal material, which had appeared as the consequence of a diarrheal episode. Together with the conspicuous alterations reported on the skin, several additional lesions and findings with clinical relevance were detected during the necropsy of N4-Keres, which are summarized in Table 1 and Fig. 1.

Dermal lesions attributable to sarcoptic mange were reported only forN4-Keres' mother (Keres), one of her sisters (N2Keres) and her brother (N3-Keres) during handling (Table 1). These lesions were mild, usually consisting of a thickening of the edge of the ear and/or localized minor skin areas with less hair density or slight scaling affecting only the face-nose area. The skin scrapings carried out allowed the detection of S. scabiei mites in N4-Keres' father (Kendo), her two sisters, and her brother (N1-Keres, N2-Keres, and N3-Keres), despite the fact that N1-Keres did not appear to have any mange compatible lesions at the moment of handling. No dermal lesions or mites have been found on skin scrapings obtained during the handling of the other lynx captured for health surveillance in the Montes de Toledo since the death of N4-Keres $(n=30)$. Table 1 summarizes the data and results regarding the handling of these two family packs, which share contiguous territories and have the same father (Kendo).

The necropsy of the four lynxes killed in traffic accidents (Kendo, N3-Keres, N4-Kuna, and O3-Luna) showed that they had good body conditions and that several traumatic lesions caused by collisions with vehicles, such as viscera/bones fractures and trauma-associated hemorrhage, were the cause of death. No dermal lesions associated with sarcoptic mange were detected during external examination, and the skin scrapings were negative. Table 1 summarizes data regarding the serological and histological results of the lynxes submitted to necropsy after the death of N4-Keres.

\section{Histology and immunohistochemistry}

The female cub N4-Keres had a severe degree of crusting dermatitis characterized by hyperkeratosis, acanthosis, a severe degeneration of the epidermal cells, and the presence of a large number of mites in the ear sample (see Table 3, Fig. 2a). The animal had moderate crusting dermatitis in the lip, periorbital, and forelimb skin samples (Fig. 2b) and mild lesions on the hind limb (Fig. 2c). Low inflammatory infiltrate consisting of lymphocytes and macrophages was observed in the lesions. IHC revealed positive immunolabeling in mites, 
Fig. 1 Most relevant macroscopical alterations reported during necropsy of the deceased female Iberian lynx cub N4-Keres. a-) General external aspect. b-) Dermal lesions reported on the face. c-) Detail of the skin lesions present in the ears. d-) Mandibular abscess affecting the right lower jaw. e-) $\mathrm{X}$-ray showing luxation of the left knee joint and fibrosis at distal femur articulation. f-) External aspect of pneumonic lungs

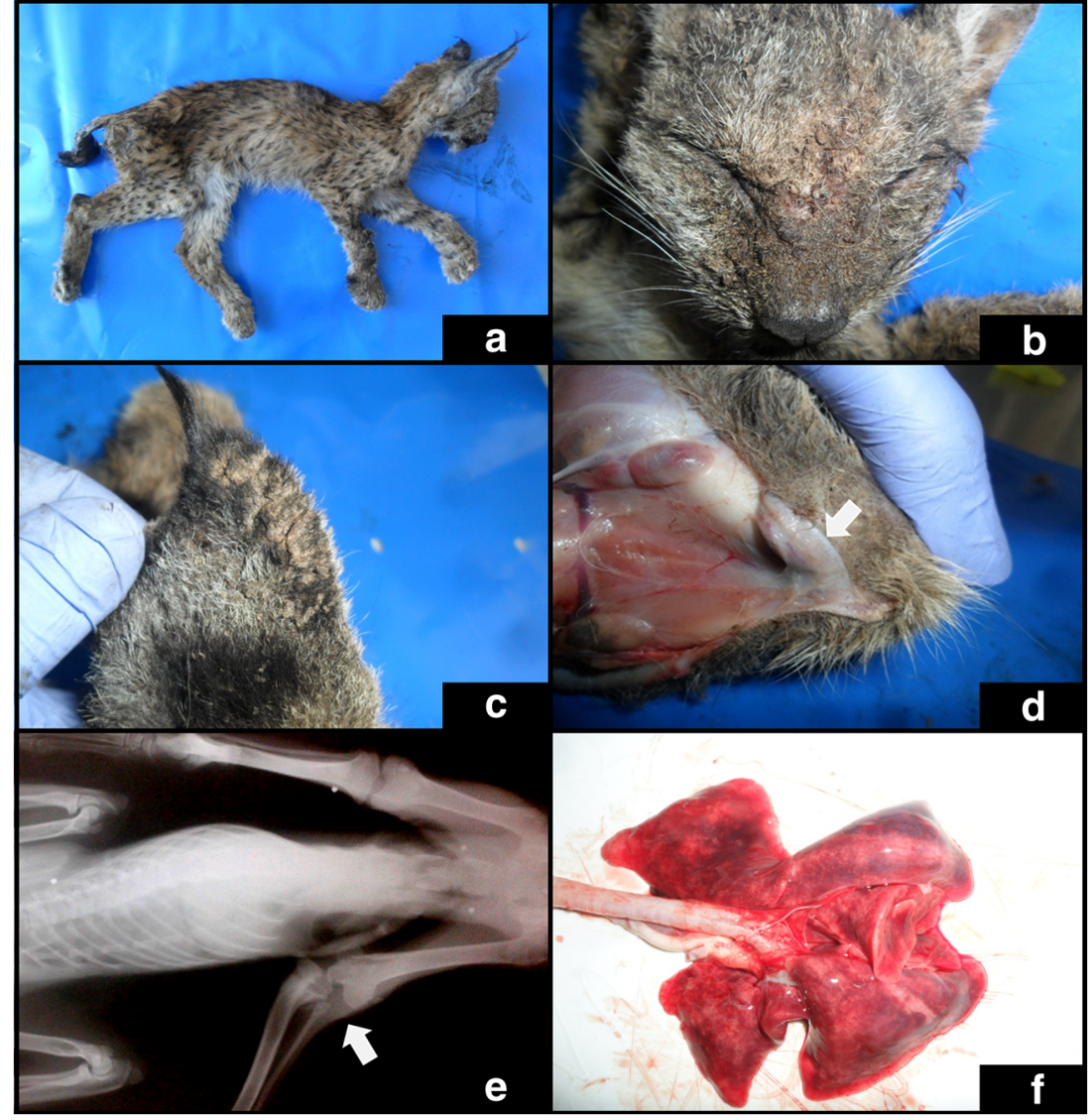

lymphocytes, and macrophages (Table 3, Fig. 2a-c). Apart from those reported on the skin, the most relevant histopathological lesions reported in N4-Keres were observed in the mandible, tongue, and lung. A purulent abscess with the presence of Gram-positive cocci was observed in the mandible, with a predominance of neutrophils and lymphocytes. The tongue had purulent ulcerative glossitis, while the lungs had edema, congestion, and acute purulent bronchopneumonia.

The remaining four lynxes (Table 1) studied at necropsy had neither histological lesions compatible with
Fig. 2 Histological (a) and immunohistochemical (b-d, using the Avidin Biotin complex-ABC - method) results obtained for Iberian lynx suffering from sarcoptic mange. a Ear. Severe hyperkeratosis, acanthosis, and presence of a large number of mites.

Hematoxilin-Eosin stain. Bar $=$ $200 \mu \mathrm{m}$. b Ear. Presence of a large number of immunolabeled mites. Bar $=200 \mu \mathrm{m}$. c Lip. Moderate crusting dermatitis with presence of few immunolabeled mites. Bar $=200 \mu \mathrm{m}$. d Hind limb. Presence of only one immunolabeled mite. Bar = $100 \mu \mathrm{m}$. Inset: positive immunolabeling within macrophages located in the dermis. Bar $=20 \mu \mathrm{m}$
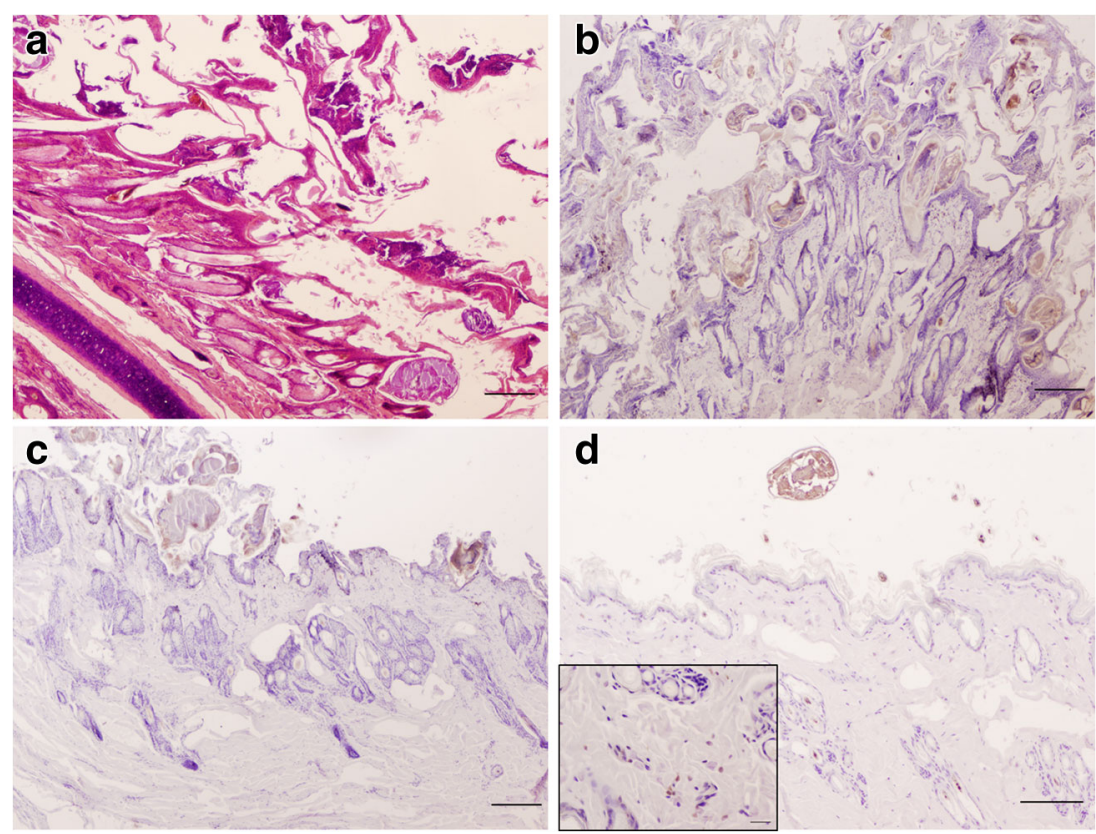
Table 2 Most relevant macroscopical findings in the necropsy of the female cub N4 Keres

\begin{tabular}{|c|c|}
\hline Affected organ & Alteration/lesion description \\
\hline Body condition & $\begin{array}{l}\text { Extremely poor body condition and generalized serous fat atrophy, } \\
\text { compatible with cachexia (picture a, Fig. 1) }\end{array}$ \\
\hline Skin & $\begin{array}{l}\text { Irregular and shabby, with crusts and fissures on the face, outer ears, nipples } \\
\text { and footpads. No alopecia (pictures a and b, Fig. 1) }\end{array}$ \\
\hline Jaw & $\begin{array}{l}\text { Subcutaneous mandibular abscess of } 2.5 \mathrm{~cm} Q \text {, affecting the right lower jaw } \\
\text { and apparently related to the fracture of the lower right canine (picture } \mathrm{c} \text {, } \\
\text { Fig. 1) }\end{array}$ \\
\hline Left knee & $\begin{array}{l}\text { Old cranial luxation of the left knee joint, with callus and severe fibrosis at } \\
\text { distal femur articulation preventing the correct flexure and extension of lef } \\
\text { lower leg (picture d, Fig. 1) }\end{array}$ \\
\hline $\begin{array}{l}\text { Subcutaneous/musculoskeletal } \\
\text { Tissues }\end{array}$ & $\begin{array}{l}\text { Presence of six round metal particles (pellets) without associated hematoma } \\
\text { (old shot): adjacent to axis }(\mathrm{Cl}) \text { and to thoracic vertebra } \mathrm{V}(\mathrm{TV}) \text {, between } \\
\text { the iliac wings, caudal to the right proximal tibia, and two in muscle of } \\
\text { ventral abdominal wall (picture d, Fig. 1) }\end{array}$ \\
\hline Linfonodes & $\begin{array}{l}\text { Generalized linfadenomegaly (especially axillary, inguinal, mandibular and } \\
\text { popliteal linfonodes) }\end{array}$ \\
\hline Abdominal cavity & Ten ml. of yellowish and translucent peritoneal fluid \\
\hline Respiratory system & $\begin{array}{l}\text { Foam and serohemic fluid in larynx and trachea. Lungs hemorrhagic, } \\
\text { emphysematosus and increased in size, compatible with pneumonia } \\
\text { (picture e, Fig. 1) }\end{array}$ \\
\hline Digestive system & $\begin{array}{l}\text { Plant material and small amount of mucus and digested blood as the only } \\
\text { content }\end{array}$ \\
\hline Spleen and adrenal glands & Increased in size, with petechia \\
\hline Liver and kidneys & Congestive \\
\hline Central nervous System & Encephalon and meninges congestive \\
\hline
\end{tabular}

mite infection nor positive immunolabeling on the skin samples, with the exception of N3-Keres, which had positive immunolabeling in scarce macrophages located on the hind limb, belly, and back. Apart from the detection of focal interstitial nephritis in O3-Luna's kidneys, no other remarkable lesions were observed in the internal organs of the four lynxes that had been run over.

Table 3 Distribution and histopathological features of sarcoptic mange lesions reported on the skin of the deceased cub N4-Keres

\begin{tabular}{lllll}
\hline Skin sample & Presence of mites & Hyperkeratosis & Inflammatory Infiltrate & IHC $^{\mathrm{c}}$ \\
\hline Ear & ++ & ++ & Few lymphocytes and macrophages & + \\
Lip & ++ & + & Few lymphocytes and macrophages & $\begin{array}{l}\text { (in mites and few lymphocytes and macrophages) } \\
\text { (in mites and few lymphocytes and macrophages) }\end{array}$ \\
Nose & - & ++ & - & -
\end{tabular}

${ }^{\text {a }}$ Presence of mites (on all slides): -: not detected; +: 1-2 mites; ++: 3-15 mites; +++: > 15 mites

${ }^{\mathrm{b}}$ Hyperkeratosis: -: none; +: mild; ++: moderate; +++: severe

${ }^{\mathrm{c}}$ IHC: Immunohistochemistry (+: positive; -: negative) 


\section{S. scabei ELISA}

The cut-off level of the ELISA test for lynx (based on sera of 11 scabies-free animals) was estimated to be 0.17 (corresponding to $17 \%$ relative $\mathrm{OD}_{450 \mathrm{~nm}}$ ) and was used to calculate the sensitivity and specificity of the test. In the Sarcoptes-free group, which was composed of 11 individuals born in captivity that had not been exposed to $S$. scabiei during their lifetime and whose skin had no dermal lesions or mite identification in scrapings, 11 out of 11 lynxes were seronegative (100\% specificity). The mean percentage of relative OD for this group was $5.52 \% \pm 3.89 \%$ (ranging from 0 to $11.19 \%$ ). N4-Keres was seropositive with a $100 \%$ relative OD. The mean OD value of the mange-free group was significantly lower than that of the mangy lynx $(p<0.05)$. We also analyzed the $\%$ of relative OD of the four lynxes that had died as the result of traffic accidents, of which N3-Keres was the only individual that, in ELISA, tested slightly above (18\%) the aforementioned cut-off rate.

\section{Additional laboratory studies}

Coprological studies, both in fresh and using the flotation concentration technique, allowed the detection of just one unidentified nematode egg in N4-Keres. The analysis of its skin samples ruled out the presence of dermatophytes related to the skin alterations reported, and toxicological analyses provided no relevant results.

The PCR tests were negative for infection with feline coronavirus ( $\mathrm{FCoV}$, intestinal scraping samples), feline calicivirus (FCV, clot samples), canine distemper virus (CDV, clot and intestinal scraping samples), feline parvovirus (FPV, intestinal scraping samples), feline herpes virus (FHV1, clot and spleen samples), feline immunodeficiency virus (FIV, clot samples), feline leukemia provirus (FeLV, clot and intestinal scraping samples), Leptospira spp. (kidney samples), and Pasteurella spp. (lung samples). The microbiological study of the mandibular abscess revealed a polymicrobial culture (including enterobacteria and clostridia) with a predominance of Streptococcus, without the presence of yeasts or fungi in samples analyzed.

\section{Discussion}

To the best of our knowledge, this article represents the first description of clinical sarcoptic mange affecting L. pardinus, namely a wild female cub found seriously ill and in which the disease was in an advanced stage. Milder mange lesions and/ or S. scabiei mites were also found in her father and her two sisters and brother.

Sarcoptes scabiei was confirmed as the causal agent of the dermal lesions found on N4-Keres by means of the isolation and identification of mites on skin scrapings, the histological detection of mites, and characteristic lesions on skin samples and also the immunohistochemical detection of mites and the immune cellular response to $S$. scabiei in skin samples. No other pathogen or compatible cause with observed skin alterations was detected.

The nature, aspect, and distribution of dermal lesions present in the deceased cub N4-Keres (Table 2) coincide with the clinical manifestations of sarcoptic mange reported for Scandinavian and Swiss lynx populations, in which the characteristic alterations in the mangy individuals consisted of thick crusts and fissures, and an extensive encrusting dermatitis that was more evident on the head, ears, feet, and tail. With regard to the Iberian lynxes affected, self-trauma and alopecia were rarely observed in mangy Eurasian lynx, while alopecia was spotty and never generalized when present. The presence of numerous mites on skin scrapings and histological sections is also a common finding in the Eurasian lynx (Pence and Ueckerman 2002; Ryser-Degiorgis et al. 2002). Histologically, the crusting dermatitis (with hyperkeratosis, acanthosis, and the degeneration of epidermal cells found on the skin) of N4-Keres agrees with the findings in the Eurasian lynx affected (Pence and Ueckerman 2002). An interesting immunohistochemical finding was the presence of positive immunolabeling of S. scabiei $\operatorname{Ss} \lambda 20 \triangle \mathrm{B} 3$ protein in the lymphocytes and macrophages of the skin samples from 6 of the 8 anatomical regions in N4-Keres (Table 3). This immunolabeling pattern in macrophagues and lymphocytes has been considered a sign of an active - and at least partially effective - cellular immune response against $S$. scabiei infestation in other wild carnivores studied in Spain (Oleaga et al. 2012).

Several macro- and microscopical alterations reported in non-dermal tissues during the necropsy of the female cub (Table 2) are common findings in severely affected mangy animals. Poor body condition and caquexia, generalized linfadenomegaly, the presence of abdominal ascitic fluid, and vascular alterations in the liver, kidneys, or subdural space have been described in several wild mammal species suffering from advanced stages of sarcoptic mange (Nakagawa et al. 2009; Espinosa et al. 2017). Alterations compatible with severe pneumonia reported during the necropsy of N4-keres and subsequently confirmed by the histopathological findings could be suggested as the final cause of death of this lynx owing to their severity. Sepsis and pneumonia (secondary to bacterial infections) related to sarcoptic mange have frequently been found in some wild species and even humans and suggested to be the definite cause of death in serious sarcoptic mange cases, as a consequence of immunosuppression (Huffam and Currie 1998; Walton and Currie 2007; Nakagawa et al. 2009; Espinosa et al. 2017). Furthermore, animals concomitantly suffering from other pathologies may 
be more prone to the clinical development of underlying scabies.

The six pellets detected in subcutaneous tissues had no associated hematoma (old shot) or apparent effect on the functioning of organs according to their location, but their possible relationship with the knee luxation found cannot be ruled out. In this respect, both the mandibular abscess and the luxation of the left knee joint should be considered as relevant findings from a clinical point of view. The subcutaneous mandibular abscess was apparently related to the fracture of the lower right canine (picture c, Fig. 1) and showed the existence of a fistula draining caudally through the right lower jaw, whose purulent material could also be related to the bronchopneumonia described. Furthermore, the ankylosed and apparently old luxation of the left knee joint prevented the correct flexure and extension of the left lower leg (Table 2, Fig. 1d) for at least several weeks before death. Since this individual was in an area without supplementary feeding support at the moment of capture, both limitations in its movement (which could have triggered hunting problems) and mastication difficulties related to the mandibular lesions could, therefore, have caused feeding problems, thus favoring malnutrition, a severe weakening of its body condition, stress and immunosupression. Although we cannot rule out the possibility of N4-Keres having come into contact with $S$. scabiei previously and the fact that the disease could have had a greater effect over time, these concomitant immunosuppressive factors may explain why N4-Keres' body condition was worse than that of the other family members affected and the effect of S. scabiei was much more serious on it.

Interestingly, only the three lynxes belonging to the family group of N4-Keres handled 20 days after the death of N4Keres had dermal lesions compatible with sarcoptic mange, along with the presence of $S$. scabiei mites on the skin scrapings, while the two other members of the family, captured 40 days after its death, had no detectable skin lesions, despite harboring S. scabiei mites (Table 1). The absence of mites and skin lesions in all the sympatric lynxes handled in $2017(n=$ 19) suggested the end of the parasitic outbreak reported in Iberian lynxes from the Montes de Toledo and coincided with the necropsy data obtained for the 4 lynxes that died in traffic accidents in 2017.

The consideration that the red fox may be the major source of sarcoptic mange infection for the Eurasian lynx (Mörner 1992; Bornstein et al. 1994; Ryser-Degiorgis et al. 2002), the existence of contacts between the Iberian lynx and sympatric red foxes (Palomares et al. 1996), and the enzootic nature of sarcoptic mange in the Spanish red fox population (Gortázar et al. 1998) suggest that this wild canid is the most plausible origin of the sarcoptic mange cases reported in the Iberian lynx discussed in this work. These same reasons lead us to hypothesize that previous cases of the transmission of sarcoptic mange to Iberian lynxes may have occurred in the field before this first description, but could have gone unnoticed owing to the hypothetical ability of immunocompetent Iberian lynxes to control this mite, and taking into account that the features of dermal lesions reported in mangy lynxes could also have hidden the disease in the field. The absence of conspicuous alopecia (Ryser-Degiorgis et al. 2002) reported in lynxes affected by sarcoptic mange can make this illness difficult to detect in the field, even through the use of camera trapping. Camera traps are widely used to monitor the Iberian lynx in the field (Guil et al. 2010; Gil-Sánchez et al. 2011), but their use would, therefore, appear to be of little value for the detection of mange compatible lesions in this species. Nevertheless, these same camera traps can undoubtedly provide valuable information about sympatric red foxes and the presence of sarcoptic mange lesions on them (Oleaga et al. 2011), thus warning about the increased risk of transmission from the red fox to the lynx on a local scale. It has been proposed that the presence of sympatric reservoirs (sarcoptic mange was confirmed in the necropsy of one red fox from the Montes de Toledo on May 25, 2016, unpublished data), together with a small population size and low genetic diversity, may increase disease-induced extinction risk for endangered species (Castro and Bolker 2005).

Despite the fact that the red fox is the most probable source of S. scabiei mites for the Iberian lynx, the possibility that the mites may come from other species such as domestic dogs and cats (Millán et al. 2007), or even rabbits (as prey after translocations or used as supplementary feeding support), cannot be ruled out. Sarcoptic mange was recently described in the wild European rabbit (Millán 2010) and wild rabbit population restocking has been identified as a potential means of dispersing or introducing sarcoptic mange into resident populations (Navarro-González et al. 2010). Molecular based research on the features and origins of mites detected in the Iberian lynx is required, not only to identify health risks for this endangered species, but also for a better understanding of the pathogenesis and evolution of sarcoptic mange in this wild cat: the genetically based preference of S. scabiei for a particular host can determine the pathogenic effect of the parasite and the evolution of the disease in a new host (Kassen 2002; Rasero et al. 2010; Oleaga et al. 2013).

N4-Keres provided a clear positive result for the ELISA developed, confirming the presence of specific antibodies against $S$. scabiei. This female cub was seriously ill, had an extremely poor body condition, and had been suffering concomitant problems for at least several weeks, which could have affected the nature and effectiveness of the immune response developed. Apart from N4-Keres, her brother, N3Keres, was the only other lynx analyzed in which the presence of antibodies against $S$. scabiei was confirmed at necropsy. The "weak" positive ELISA result (obtained for N3-Keres more than 200 days after its first handling, when the sarcoptic mange lesions and mites had been found and treated, Table 1) 
is difficult to interpret, and one of the possible explanations is a recent reinfection. More samples and research are necessary for a better adjustment and validation of the ELISA developed and a correct understanding of the Iberian lynx's humoral immune response against $S$. scabiei. Nevertheless, the promising results obtained suggest the value of the ELISA developed for the health surveillance of the Iberian lynx, and its possible usefulness as a monitoring tool for the detection and evaluation of exposure to $S$. scabiei of this species in the field over time.

The treatment administered to all the animals handled prevented a more in-depth exploration of the epidemiology and natural evolution of detected clinical cases, thus preventing us from, for example, distinguishing between mite control or recent infestation in those animals without skin damage but in which the presence of mites was confirmed. However, both Ivermectin (for adults) and Selamectine (for cubs) appeared to be safe and effective (at least for the parasite burdens present in the animals treated in the present work) in a single dose, according to the data obtained. The thorough monitoring and frequent handlings to which Iberian lynxes are subjected could allow the capture and effective treatment of individual cases as it has been reported in other threatened species (Young et al. 1972; Pence et al. 1982), but the eradication of mange in the field is not feasible, since other affected sympatric species are abundant and are a possible frequent source of mites (Bornstein et al. 2001; Millán et al. 2007). In the specific case of the Iberian lynx, the use of ectoparasitic treatments should also take into account the existence and conservation needs of Felicola isidoroi, a host-specific louse of Lynx pardinus, which has been suggested to be scarcer and, therefore, even more endangered than its host (Pérez et al. 2013; Jørgensen 2014).

Some results collected in the present work, such as (i) necropsy data regarding N4-Keres (showing concomitant lesions with a possible immunosuppressive effect, and an active cellular immune response against S. scabiei); (ii) the limited extent and severity of lesions found in other affected Iberian lynxes handled after the death of N4-Keres; (iii) necropsy findings in four of those that were available after death as the result of traffic accidents; and (iv) the absence of new detected lynxes with mange compatible lesions or Sarcoptes mites in the study area to date, suggest that the Iberian lynx population from the Montes de Toledo has a certain ability to control this outbreak. However, this local outbreak and its evolution, as studied in the present work, should not be considered as evidence of the Iberian lynx's real ability to avoid or control this disease. The existence of different situations, ecological features, and health threats prevents the extrapolation of data among different populations within the same species (López et al. 2014). This presence of different health threats in different populations could explain the fact that the first descriptions of two new pathogen agents for the Iberian lynx, i.e., Pseudorabies virus (detected in 2015, Masot et al. 2017) and S. scabiei (detected in 2016, as shown in this work) have been reported in cubs born in the first year with confirmed reproduction in Extremadura (SW Spain) and Castilla La Mancha (Central Spain), respectively, from which the species had disappeared and was reintroduced in 2014 (LIFE10NAT/ ES/570).

Apart from the proposed underlying inbreeding-mediated immunosuppression (Peña et al. 2006; Palomares et al. 2012; López et al. 2014) and the various factors that provoke situations of long-lasting stress, diseases are considered an important threat, and several immunosuppressive pathogen agents may potentially affect the Iberian lynx (Meli et al. 2009; Millán et al. 2009; López et al. 2014). As has been proposed for other wild carnivore species (Oleaga et al. 2015), the concomitance of $S$. scabiei with other pathogenic agents may worsen the pathogenic effect of sarcoptic mange at an individual and also a population level, thus enabling a different evolution and relevance of the same parasite in different populations.

\section{Conclusion}

Sarcoptic mange has been proposed to have a scarce longterm effect and impact at the population level on freeranging stable populations (Pence and Ueckerman 2002; Ryser-Degiorgis et al. 2005a, c), but the presence of a few cases could threaten the long-term survival of a small, isolated, and inbred population like that of the Iberian lynx (Schmidt-Posthaus et al. 2002). Data obtained in this first outbreak suggest a limited effect of $S$. scabiei on immunecompetent Iberian lynxes in the local population of the Montes de Toledo, at least during the first stages of the disease, and a good and apparently definitive recovery after treatment. However, a different evolution and relevance of sarcoptic mange in different populations, or even in the same one when confronted with immunosuppressive factors - such as other immunosuppressive infectious diseases - cannot be ruled out, which could trigger more serious consequences. In this respect, the fact that sarcoptic mange has been considered the most frequent infectious disease affecting the Eurasian lynx in Central Europe should warn us about its possible relevance for the Iberian lynx. Health surveillance works carried out on this wild cat and sympatric species that potentially share parasites with it are key tools for the early detection of health risks, and would, if necessary, allow the implementation of preventive or corrective measures. Further research is, therefore, required for a complete understanding of the epidemiology and real threat that this ectoparasitic disease may imply for L. pardinus. 
Acknowledgements This work has been possible thanks to the collaboration of the "Consejería de Agricultura, MedioAmbiente y Desarrollo Rural" of Castilla-La Mancha, and to the Life+Iberlince project "Recuperación de la distribución histórica del Lince ibérico (Lynxpardinus) en España y Portugal" (LIFE10NAT/ES/570).

We would like to thank Manolo Mata (Fomecam), Francisco Sánchez (Geacam), Juan Francisco Ruiz (Fomecam), Cristina Rodriguez (Fomecam), the Environmental Agents of JCCM and all the team members of Fomecam for the fieldwork developed, and our colleagues at the "Centro de Análisis y Diagnóstico de la Fauna Silvestre (CAD)" and "Laboratorio Regional Agroalimentario y Ambiental de Castilla-La Mancha (LARAGA)" for their laboratory work. We also wish to thank Sally Newton for revising the English in the manuscript.

\section{Compliance with ethical standards}

Conflict of interest The authors declare that they have no conflict of interest.

Ethical approval All applicable international, national, and/or institutional guidelines for the care and use of animals were followed.

\section{References}

Abascal F, Corvelo A, Cruz F, Villanueva-Cañas JL, Vlasova A, MarcetHouben M, Martínez-Cruz B, Cheng JY, Prieto P, Quesada V, Quilez J, Li G, García F, Rubio-Camarillo M, Frias L, Ribeca P, CapellaGutiérrez S, Rodríguez JM, Câmara F, Lowy E, Cozzuto L, Erb I, Tress ML, Rodriguez-Ales JL, Ruiz-Orera J, Reverter F, CasasMarce M, Soriano L, Arango JR, Derdak S, Galán B, Blanc J, Gut M, Lorente-Galdos B, Andrés-Nieto M, López-Otín C, Valencia A, Gut I, García JL, Guigó R, Murphy WJ, Ruiz-Herrera A, MarquesBonet T, Roma G, Notredame C, Mailund T, Albà MM, Gabaldón T, Alioto T, Godoy JA (2016) Extreme genomic erosion after recurrent demographic bottlenecks in the highly endangered Iberian lynx. Genome Biol 17:251

Bornstein S, Wallgren P (1997) Serodiagnosis of sarcoptic mange in pigs. Vet Rec 141:8-12

Bornstein S, Röken B, Lindberg R,Krüger T (1994) Sarcoptic mange of lynx (Felis lynx): an experimental infection with Sarcoptes scabiei var. vulpes. Viltpatologmöte, Eckerö, Åland, Sweden, 18-20.05, pp 3-4

Bornstein S, Mörner T, Samuel WM (2001) Sarcoptes scabiei and sarcoptic mange. In: Samuel WM, Pybus MJ, Kocan AA (eds.) Parasitic diseases of wild mammals, 2nd ed. Iowa State University Press, Ames, pp 107-119

Calvete C, Estrada R, Villafuerte R, Lucientes J, Osácar JJ (2002) Epidemiology of viral hemorrhagic disease (VHD) and myxomatosis in the wild rabbit (Oryctolagus cuniculus) in the mid-Ebro Valley,Spain. Vet Rec 150:776-782

Casais R, Prieto M, Balseiro A, Solano P, Parra F, Martín Alonso JM (2007) Identification and heterologous expresión of a Sarcoptes scabiei cDNA encoding a structural antigen with immunodiagnostic potential. Vet Res 38:435-450

Casais R, Goyena E, Martínez-Carrasco C, Ruiz de Ybáñez R, Alonso de Vega F, Ramis G, Prieto JM, Berriatua E (2013) Variable performance of a human derived Sarcoptes scabiei recombinant antigen ELISA in swine mange diagnosis. Vet Parasitol 197:397-403

Casais R, Millán J, Rosell JM, Dalton KP, Prieto JM (2015) Evaluation of an ELISA using recombinant $S s \lambda 20 \triangle B 3$ antigen for the serological diagnosis of Sarcoptes scabiei infestation in domestic and wild rabbits. Vet Parasitol 214(3-4):315-321
Castro FD, Bolker B (2005) Mechanisms of disease-induced extinction. Ecol Lett 8:117-126

Espinosa J, Ráez-Bravo A, López-Olvera JR, Pérez JM, Lavín S, Tvarijonaviciute A, Cano-Manuel FJ, Fandos P, Soriguer RC, Granados JE, Romero D, Velarde R (2017) Histopathology, microbiology and the inflammatory process associated with Sarcoptes scabiei infection in the Iberian ibex, Capra pyrenaica. Parasit Vectors 10:596

Falconi C, Oleaga A, López-Olvera J, Casais R, Prieto M, Gortázar C (2010) Prevalence of antibodies against selected agents shared between Cantabrian chamois (Rupicapra pyrenaica parva) and domestic goats. Eur J Wildl Res 56:319-325

Geret CP, Cattori V, Meli ML, Riond B, Martínez F, López G, Vargas A, Simón MA, López-Bao JV, Hofmann-Lehmann R, Lutz H (2011) Feline leukemia virus outbreak in the critically endangered Iberian lynx (Lynx pardinus): high- throughput sequencing of envelope variable region a and experimental transmission. Arch Virol 156:839854

Gil-Sánchez JM, Moral M, Bueno J, Rodríguez-Siles J, Lillo S, Pérez J, Martín JM, Valenzuela G, Garrote G, Torralba B, Simón-Mata MÁ (2011) The use of camera trapping for estimating Iberian lynx (Lynx pardinus) home ranges. Eur J Wildl Res 57(6):1203-1211

Gortázar C, Villafuerte R, Blanco JC, Fernández de Luco D (1998) Enzootic sarcoptic mange in red foxes in Spain. Z Jagdwiss 44: 251-256

Guil F, Agudín S, El-Khadir N et al (2010) Factors conditioning the camera-trapping efficiency for the Iberian lynx (Lynx pardinus). Eur J WildlRes 56:633-640

Hofmann-Lehmann R, Fehr D, Grob M et al (1996) Prevalence of antibodies to feline parvovirus, calicivirus, herpesvirus, coronavirus, and immunodeficiency virus and of feline leukemia virus antigen and the interrelationship of these viral infections in free-ranging lions in East Africa. Clin Diagn Lab Immunol 3:554-562

Hollanders W, Vercruysse J, Raes S, Bornstein S (1997) Evaluation of an enzyme-linked immunosorbent assay (ELISA) for the serological diagnosis of sarcoptic mange in swine. Vet Parasitol 69:117-123

Huffam SE, Currie BJ (1998) Ivermectin for Sarcoptes scabiei hyperinfestation. Int J Infect Dis 2:152-154

Jacobson RH (1998) Validation of serological assays for diagnosis of infectious diseases. Rev Sci Tech 17:469-486

Johnson WE, Godoy JA, Palomares F, Delibes M, Fernandes M, Revilla E, O'Brien SJ (2004) Phylogenetic and phylogeographic analysis of Iberian lynx populations. J Hered 95:19-28

Jørgensen D (2014) Conservation implications of parasite coreintroduction. Conserv Biol 2:602-604

Kalema-Zikusoka G, Koch RA, Macfie EJ (2002) Scabies in freeranging mountain gorillas (Gorilla berengei berengei) in Bwindi impenetrable National Park, Uganda. Vet Rec 150:12-15

Kassen R (2002) The experimental evolution of specialists, generalists, and the maintenance of diversity. J Evol Biol 15:173-190

López G, López-Parra M, Garrote G, Fernández L, del Rey-Wamba T, Arenas-Rojas R, García-Tardío M, Ruiz G, Zorrilla I, Moral M, Simón MA (2014) Evaluating mortality rates and causalities in a critically endangered felid across its whole distribution range. Eur J Wildl Res 60:359-366

Martin RW, Handasyde KA, Skerratt LF (1998) Current distribution of sarcoptic mange in wombats. Aust Vet J 76:411-414

Masot AJ, Gil M, Risco D, Jiménez OM, Nuñez JI, Redondo E (2017) Pseudorabies virus infection (Aujeszky's disease) in an Iberian lynx (Lynx pardinus) in Spain: a case report. BMC Vet Res 13:6

Meli ML, Cattori V, Martínez F, López G, Vargas A, Simón MA, Zorrilla I, Muñoz A, Palomares F, López-Bao JV, Pastor J, Tandon R, Willi B, Hofmann-Lehmann R, Lutz H (2009) Feline leukemia virus and other pathogens as important threats to the survival of the critically endangered Iberian lynx (Lynx pardinus). PLoS One 4:e4744 
Meli ML, Cattori V, Martínez F, López G, Vargas A, Palomares F, LópezBao JV, Hofmann-Lehmann R, Lutz H (2010) Feline leukemia virus infection: a threat for the survival of the critically endangered Iberian lynx (Lynx pardinus). Vet Immunol Immunopathol 134:61-67

Millán J (2010) First description of sarcoptic mange in wild European rabbit (Oryctolagus cuniculus). Eur J Wildl Res 56:455-457

Millán J, Ruiz-Fons F, Márquez FJ, Viota M, López-Bao JV, MartínMateo MP (2007) Ectoparasites of the endangered Iberian lynx Lynx pardinus and sympatric wild and domestic carnivores in Spain. Med Vet Entomol 21:248-254

Millán J, Candela MG, Palomares F, Cubero MJ, Rodríguez A, Barral M, de la Fuente J, Almería S, León-Vizcaíno L (2009) Disease threats to the endangered Iberian lynx (Lynx pardinus). Vet J 182:114-124

Mörner T (1992) Sarcoptic mange in Swedish wildlife. Rev Sci Tech 11: $1115-1121$

Munson L, Terio KA, Ryser-Degiorgis MP, Lane EP, Courchamp F (2010) Wild felid diseases: conservation implications and management strategies. In: Macdonald DW, Loveridge AJ (eds) Biology and conservation of wild felids. Oxford University Press, Oxford, pp 237-262

Nakagawa TLDR, Takai Y, Kubo M, Sakai H, Masegi T, Yanai T (2009) A pathological study of Sepsis associated with Sarcoptic mange in raccoon dogs (Nyctereutes procyonoides) in Japan. J Comp Pathol 141:177-181

Navarro-González N, Serrano E, Casas-Díaz E, Velarde R, Rossi L, Marco I, Lavín S (2010) Game restocking and the introduction of sarcoptic mange in wild rabbit in northeastern Spain. Anim Conserv 13:586-591

Oleaga A, Casais R, González-Quirós P, Prieto M, Gortázar C (2008) Sarcoptic mange in red deer from Spain: improved surveillance or disease emergence? Vet Parasitol 154:103-113

Oleaga A, Casais R, Balseiro A, Espí A, Llaneza L, Hartasánchez A, Gortázar C (2011) New techniques for an old disease: sarcoptic mange in the Iberian wolf. Vet Parasitol 181:255-266

Oleaga A, Casais R, Prieto JM, Gortázar C, Balseiro A (2012) Comparative pathological and immunohistochemical features of Sarcoptic mange in five sympatric wildlife species in northern Spain. Eur J Wildl Res 58:997-1000

Oleaga A, Alasaad S, Rossi L, Casais R, Vicente J, Maione S, Gortázar C (2013) Genetic epidemiology of Sarcoptes scabiei in the Iberian wolf in Asturias, Spain. Vet Parasitol 196(3-4):453-459

Oleaga A, Vicente J, Ferroglio E, Pegoraro de Macedo MR, Casais R, del Cerro A, Espí A, García EJ, Gortázar C (2015) Concomitance and interactions of pathogens in the Iberian wolf (Canis lupus). Res Vet Sci 101:22-27

Palomares F, Ferreras P, Fedriani JM, Delibes M (1996) Spatial relationships between Iberian lynx and other carnivores in an area of southwestern Spain. J Appl Ecol 33:5-13

Palomares F, Godoy JA, López-Bao JV, Rodríguez A, Roques S, CasasMarce M, Revilla E, Delibes M (2012) Possible extinction vortex for a population of Iberian lynx on the verge of extirpation. Conserv Biol 26:689-697

Peña L, García P, Jiménez MA, Benito A, Alenza MDP, Sánchez B (2006) Histopathological and immunohistochemical findings in lymphoid tissues of the endangered Iberian lynx (Lynx pardinus). Comp Immunol Microbiol Infect Dis 29:114-126

Pence DB, Ueckerman E (2002) Sarcoptic mange in wildlife. Rev Sci Tech 21:385-398

Pence DB, Matthews FD, Windberg LA (1982) Notoedric mange in the bobcat, Felis rufus, from South Texas. J Wildl Dis 18:47-50

Pérez JM, Sánchez I, Palma RL (2013) The dilemma of conserving parasites: the case of Felicola (Lorisicola) isidoroi (Phthiraptera:
Trichodectidae) and its host, the endangered Iberian lynx (Lynx pardinus). Insect Conserv Divers 6:680-686

Prieto JM, Balseiro A, Casais R, Abendaño N, Fitzgerald LE, Garrido JM, Juste RA, Alonso-Hearn M (2014) Sensitive and specific enzyme-linked immunosorbent assay for detecting serum antibodies against Mycobacterium avium subsp. Paratuberculosis in fallow deer. Clin Vaccine Immunol 21:1077-1085

Ramsauer S, Bay G, Meli M, Hofmann-Lehmann R, Lutz H (2007) Seroprevalence of selected infectious agents in a free-ranging, low-density lion population in the central Kalahari game reserves in Botswana. Clin Vaccine Immunol14:808-810

Rasero R, Rossi L, Maione S et al (2010) Host taxon-derived Sarcoptes mites in European wildlife animals, revealed by microsatellite markers. Biol Conserv 143:1269-1277

Rodríguez A, Calzada J (2015) Lynx pardinus. The IUCN red list of threatened species 2015:e.T12520A50655794. https://doi.org/10. 2305/IUCN.UK.2015-2.RLTS.T12520A50655794.en. Accessed 17 Mar 2018

Ryser-Degiorgis M-P, Ryser A, Bacciarini LN, Angst C, Gottstein B, Janovsky M, Breitenmoser U (2002) Notoedric and sarcoptic mange in free-ranging lynx from Switzerland. J Wildl Dis 38:228-232

Ryser-Degiorgis M-P, Bröjer C, HårdafSegerstad C et al (2005a) Assessment of the health status of the free-ranging Eurasian lynx population in Sweden. Proceedings of the 1st workshop on lynx veterinary aspects, Doñana, 4-6 November. Ministry of the Environment, Spain, p 2005

Ryser-Degiorgis M-P, Hofmann-Lehmann R, Leutenegger CM, Hårdaf Segerstad C, Mörner T, Mattsson R, Lutz H (2005b) Epizootiologic investigations of selected infectious disease agents in free-ranging Eurasian lynx from Sweden. J Wildl Dis 41:58-66

Ryser-Degiorgis M-P, Robert N, Lutz H, Sager H, Augsburger M, Breitenmoser U, Breitenmoser-Würsten C (2005c) Causes of mortality and diseases in re-introduced populations of Eurasian lynx (Lynx lynx) in Switzerland. Proceedings of the 1st workshop on lynx veterinary aspects, Doñana, 4-6 November, 2005. Ministry of the Environment, Spain

Sanchez J, Dohoo IR, Markham F, Leslie K, Conboy G (2012) Evaluation of the repeatability of a crude adult indirect Ostertagia ostertagi ELISA and methods of expressing results. Vet Parasitol 109:75-90

Schmidt-Posthaus H, Breitenmoser-Würsten C, Posthaus H, Bacciarini L, Breitenmoser U (2002) Causes of mortality in reintroduced Eurasian lynx in Switzerland. J Wildl Dis 38(1):84-92

Simon MA (2017) Censo de las poblaciones de lince ibérico, año 2016. Life+ Iberlince website,2017.http://www.iberlince.eu. Accessed 11 Feb 2018

von Arx M, Breitenmoser-Würsten C, Zimmermann F, Breitenmoser U (2004) Status and conservation of the Eurasian lynx (Lynx lynx) in Europe in 2001. KORA Bericht Nr. 19

Wall R, Shearer D (1997) Veterinary entomology. Chapman and Hall, London

Walton SF, Currie BJ (2007) Problems in diagnosing scabies: a global disease in human and animal populations. Clin Microbiol Rev 20: 268-279

Young E, Zumpt F, Whyte IJ (1972) Notoedres cati infestation of the cheetah: preliminary report. JS Afr Vet Assoc 43:205

Zimmermann W, Kircher P (1998) SerologischeBestandesuntersuchung und Sanierungsüberwachung der Sarcoptesscabiei var. suisInfektion: erstevorläufigeResultate, Schweiz Arch Tierheilk 140:513-517

Publisher's note Springer Nature remains neutral with regard to jurisdictional claims in published maps and institutional affiliations. 